\title{
DUCTILITY OF STEEL-FIBRE-REINFORCED RECYCLED LIGHTWEIGHT CONCRETE
}

\author{
Hasanain Al-Naimi, Ali Abbas \\ School of Architecture, Computing and Engineering \\ University of East London \\ E16 2RD, UK \\ \{u1637128, abbas\}@uel.ac.uk
}

\begin{abstract}
This work examines experimentally and numerically the influence of steel fibre reinforcement on lightweight aggregate concrete ( $L W A C)$. The replacement of conventional aggregates with recycled lightweight ones has several benefits such as reducing the mass of the structure leading to more economical designs (also beneficial under earthquake loading). The experimental project showed that it was possible to produce higher strength to weight ratio of LWAC compared to normal weight aggregate concrete (NWAC) as dry densities were approximately 700 $\mathrm{Kg} / \mathrm{m} 3$ lower for identical characteristic compressive strengths between 40MPa and 30MPa. This could lead to savings in materials, construction and transportation costs making it especially useful and economical for long-span and seismic-resistant structures. Conversely, LWAC is noted for its highly brittle nature due to its associated weak aggregate interlock mechanism which can be typically compensated for by increasing shear reinforcement and dowel action by means of adding higher reinforcement ratios. Nonetheless, this creates several challenges in construction such as congestion of reinforcement in critical regions as well as increased dead loads which render LWAC use counterproductive. Thus, steel fibre reinforcement emerges as a promising solution where partial or total substitution of conventional transverse reinforcement could become a possibility. This project carries out examination of the effectiveness of hooked-end steel fibre reinforcement with fibre volume fractions of Vf = $1 \%$ and $V f=2 \%$. The experimental investigation includes the study of direct uniaxial compression and tension (unique pullout test) and indirect splitting and flexural tensile tests. Moreover, a nonlinear finite element study has been carried out using ABAQUS to model the experiments using CDP. Currently, there is no international standards or design guidelines for steel fibre reinforced lightweight concrete (SFRLC). This project will help address that and lead to sustainable and innovative seismic design solutions in the future.
\end{abstract}

Keywords: Recycled lightweight concrete, Hooked-end steel fibres, ABAQUS, Ductility, Flexural beam test, Pullout. 


\section{INTRODUCTION}

Today, the use of structural lightweight aggregate concrete has become attractive especially as a precast material due to advantages which mainly involve the reduction in structural weight as compared to normal weight aggregate concrete. This in turn results in a decrease in the amount of reinforcement required, material transport costs and in the cross section of structural members especially columns, beams, walls and foundations which leads to reduced inertial and gravity loads and the catering for the growing need for taller and longer span structures. This is especially beneficial for seismic structures. In this sense, LWAC can grow to be competitive against NWC (Libre et al., 2011; Campione, 2014; Dias-Da-Costa, 2014; Mo et al., 2017). Although the price for lightweight concrete per $\mathrm{m}^{3}$ can be higher than that of normal weight concrete, the overall cost of the structure due to the aforementioned savings can be substantially reduced with increased structural performance for an equivalent normal concrete structure. Kang and Kim (2010) report overall savings of $10 \%$ to $20 \%$. Other advantages of lightweight concrete include reduction in carbon emissions and providing solutions to the lack of sufficient gravel and quarry resources foreseen in the imminent future (Gerritse, 1981).

Concrete in general and lightweight in particular is a brittle material which lacks material toughening mechanisms such as aggregate interlock. This makes LWAC susceptible to cracking and sudden brittle failure. To address the latter and enhance ductility, steel-bar reinforcement is usually incorporated in structural elements. However, due to the brittle nature of lightweight concrete this may become impractical and inherently counterproductive as a large number of reinforcement bars coupled with stirrups may increase the total weight of the structure and lead to difficulties in placing them within critical zones in concrete section during construction. Therefore, fibre reinforcement which has long proven its effectiveness in controlling and bridging tensile and shear cracks in the past for both lightweight and normal weight concretes can become an adequate solution (Gao et al., 1997; Balendran et al., 2002; Campione and La Mendola, 2004; Abbas et al., 2014a; Di Prisco, Colombo and Dozio, 2013; Grabois et al., 2016).

Steel fibre reinforced concrete is a composite material defined mainly by improved post cracking tensile behaviour due to the capability of fibres to bridge the crack faces preventing their propagation and widening into bigger cracks. This crack control mechanism leads to improved toughness, ductility and flexural and shear load carrying capacity (Swamy, Jones and Chiam, 1993; Kang and Kim, 2010; Di Prisco, Colombo and Dozio, 2013; Iqbal et al., 2015; Grabois et al., 2016). Unlike plain concrete, fibrous concrete can display tension softening or tension hardening depending on fibre dosage which leads to enhanced energy dissipation and ductility. Also, since cracking due to shrinkage is present naturally in concrete even prior to loading, fibres can be used to control cracking due to all types of shrinkage (Libre et al., 2011). The mechanical properties of SFRC are governed essentially by the bond strength between matrix and steel fibres, their dispersion, location, orientation, volume fraction and type (geometry and aspect ratio) (Concrete Society, 2007; Di Prisco, Colombo and Dozio, 2013).

Even though the advantages of the usage of fibrous concrete has been reported for over 40 years (Ritchie and Kayali, 1975), comprehensive studies on SFRLC (especially with modern fibres) is still largely scarce with most of the current work being merely theoretical and SFRC-based. It should also be noted that currently, there is no international standards or design guidelines for steel fibre reinforced lightweight concrete (SFRLC). This work will help pave the path for the latter. 
This project suggests a comprehensive methodology to test lightweight fibrous concrete both on the meso- and micro-scale levels experimentally and numerically.

\section{EXPERIMENTAL LABORATORY WORK}

\subsection{Experimental Programme}

The experimental programme comprises tensile and compressive tests on lightweight and fibrous concretes. The aim is to study the influence of the incorporation of fibres into the lightweight mix on the mesoscale level (compression tests, direct fibre pullout tests) and macroscale level (flexural beam tests). The philosophy behind the experimental testing and its parameters can be seen in the table 1 below. As mentioned previously, the experimental programme will include a variety of specimen types. For uniaxial compression tests, both cylinders and cubes ( 3 per mix) are used and compared besides prisms to evaluate Modulus of Elasticity, Poisson's ratio, compressive ductility and to study the effect of fibres on short columns. For tensile tests, direct pullout cubes ( 2 per mix) will be tested to evaluate the direct tensile behaviour of plain and fibrous lightweight concrete while indirect tensile tests on splitting cylinders ( 3 per mix) and unnotched and notched beams will be carried out to study the material and flexural and shear behaviour of LWAC and SFRLC.

\begin{tabular}{|c|c|c|c|c|c|c|}
\hline \multirow[b]{2}{*}{$\begin{array}{c}\text { Mi } \\
\mathbf{x}\end{array}$} & \multicolumn{5}{|c|}{ Parameters } & \multirow[b]{2}{*}{ Aims } \\
\hline & $V_{f}(\%)$ & $\begin{array}{l}\text { Fibre } \\
\text { type }\end{array}$ & $\mathbf{f}_{\text {ck }} / \mathbf{f}_{\text {ck,cube }}$ & $\begin{array}{l}\text { Reinforce- } \\
\text { ment layout }\end{array}$ & $\begin{array}{l}\text { Stirrups } \\
\text { spacing }\end{array}$ & \\
\hline 1.1 & 0 & N/A & \multirow{4}{*}{$\mathrm{LC} 30 / 33$} & \multirow{3}{*}{$\begin{array}{l}\text { 2T12@ Bot; } \\
\text { 2T6@ Top }\end{array}$} & \multirow{3}{*}{$\begin{array}{l}\text { R6 @ } 120 \mathrm{~mm} \\
\& 240 \mathrm{~mm}\end{array}$} & $\begin{array}{l}\text { Study the behaviour of plain } \\
\text { concrete }\end{array}$ \\
\hline 1.2 & 1 & & & & & Study the effect of increasing \\
\hline 1.3 & 2 & $3 \mathrm{D}$ & & & & $\begin{array}{l}\text { fibre dosage and potential re- } \\
\text { placement of stirrups with fi- } \\
\text { bres in beams }\end{array}$ \\
\hline 1.4 & 1 & $5 \mathrm{D}$ & & & & $\begin{array}{l}\text { Study the effect of the modern } \\
5 \mathrm{D} \text { fibres on the behaviour of } \\
\text { concrete }\end{array}$ \\
\hline 1.5 & 0 & \multirow{2}{*}{$3 \mathrm{D}$} & \multirow{2}{*}{ LC35/38 } & & & Study the effect of fibres on a \\
\hline 1.6 & 1 & & & & & different concrete strength \\
\hline
\end{tabular}

Table 1: Summary of parameters used in experimental testing

The testing programme encompasses the study of 3 types of concrete strengths, 2 different steel fibres, 2 different fibre dosage $V_{f}$ and 2 different steel cages. Steel fibres were either 3D or 5D. This was the case because hooked-end 3D fibres are currently the most commonly used in industry (Abdallah et al., 2018) and will be used as the base of experiments while modern hooked-end 5D fibres with more extensive hooks than the typical hooked-end 3D fibres are considered to be the strongest. Moreover, DRAMIX claim that this type of fibre is capable of replacing primary reinforcement in beams. Fibre dosages of $1 \%$ and $2 \%$ are chosen for testing. This is the case since most common structures such as tunnels and pavements require at least a dosage of $\mathrm{V}_{\mathrm{f}}=1 \%$ for efficient crack control and thickness reduction (The concrete Society, 2007). Also, 2 different stirrups spacing was used. A spacing of $120 \mathrm{~mm}$ is valid to EC2 shear design and the beam should thus fail in flexure while a spacing of $240 \mathrm{~mm}$ is inadequate according to EC2 and the beam should thus fail in shear. The cross sections for the beams are shown in figure 1. Also, a relatively low reinforcement ratio in tension $(\rho=0.0018)$ 
was used to study the flexural effect of fibres on concrete beams. This was similar to the reinforcement ratio used by Kodur et al. (2019).

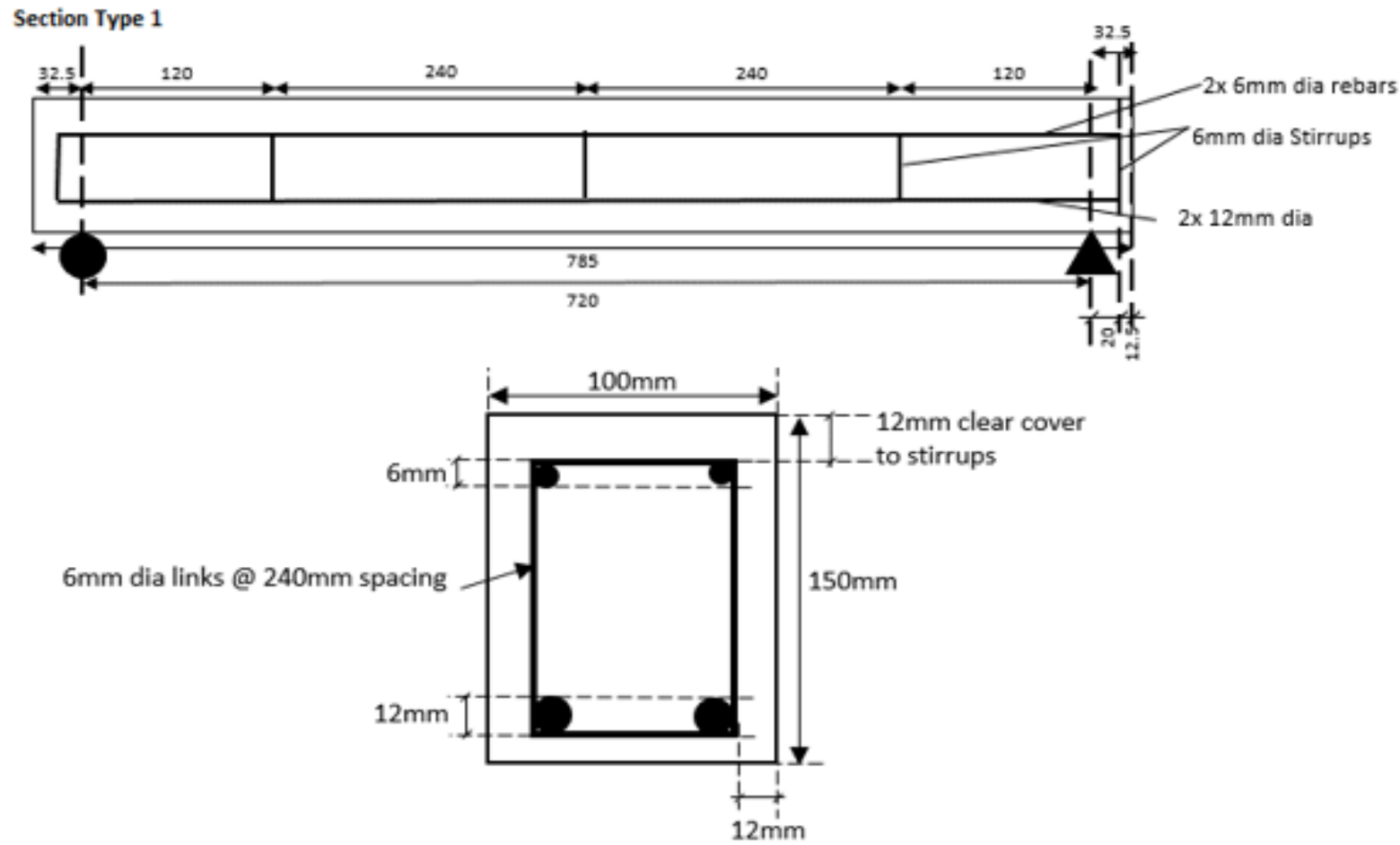

Section type 1

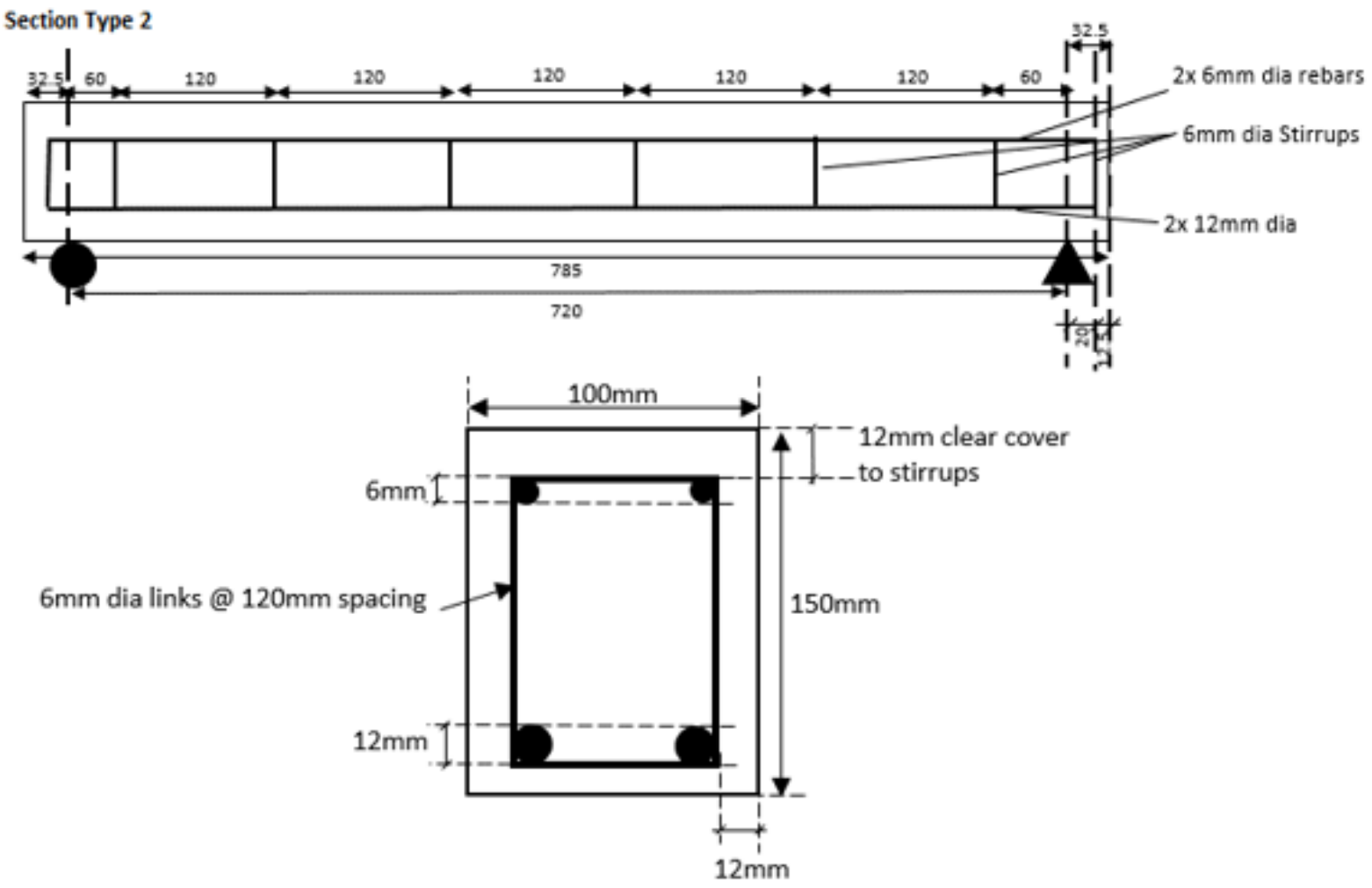

Section type 2

Figure 1: Longitudinal and cross-sectional sections for the beams tested 


\subsection{Experimental tests}

The experiments include splitting tensile, the pullout test, compression cylinder and flexural beam tests. The Splitting tensile tests on cylinder specimens will be performed according to BS EN 12390-6. A direct uniaxial tensile fibre pull-out test was designed to study the effect of the embedded fibre onto the direct tensile stress-crack width of the concrete. Unlike Robins et al (2002) pullout test, the test is designed to have the fibre completely embedded in Lytag concrete. To ensure breakage of the specimen in tension at the monitored middle section, this section of the concrete was reduced to a diameter corresponding to the area a single DRAMIX fibre is predicted to occupy in the concrete. This area was determined using numerical and statistical models which depend mainly on fibre geometry and fibre volume fraction and take random distribution and dispersion of fibres into account (Krenchel et al., 1975; Romualdi and Mendel, 1964; Soroushian and Lee, 1990). Hence, this test can be regarded as a truer and more realistic pullout test than the classical pullout test with the fibre embedded on 1 side while the other end of the fibre is clamped by the machine (Abdallah et al., 2018). The pullout specimen is carefully placed in a tensile testing machine equipped with an in-built calibrated displacement transducer which will be used to measure the deformation histories of the effective section of the pullout specimens with a load cell where the two steel bars from each end are securely gripped in a way to disallow any superfluous slip. While one end is fixed, the other will be gradually pulled in tension at a displacement-controlled loading.

Due to their uniform stress distribution and adequate confinement, cylinders are the chosen specimens to test for compression and thus generate the complete compressive stress-strain behaviour for lightweight plain and fibrous concrete. A calibrated compressometerextensometer steel ring designed according to ASTM C 469 and fitted with LVDT's is clamped onto the concrete cylinders. For the flexural beam tests the LVDTs were glued using high strength epoxy after the concrete surface in touch with the LVDT was ground in the midsection at the front of the beam to enable the LVDTs to fully adhere onto the concrete. The LVDT's are connected to a computer software. For the purpose of estimating the vertical deflection accurately, a steel bar inspired by a technique similar to JSCE-SF4 recommendations was made. The beams are placed onto two frictionless steel supports. This was deemed adequate as the loading was symmetrical. A displacement controlled constant loading of $0.2 \mathrm{~mm} / \mathrm{min}$ was adopted using the hydraulic machine which has a load capacity of $500 \mathrm{kN}$. It should be noted that the machine is also supplied with a calibrated displacement transducer.

\section{NUMERICAL PROGRAMME}

\subsection{FEM approach}

The 3D NLFEM analyses (Zienkiewicz and Taylor, 2005) will be carried out using the finite element package ABAQUS (Habbit et al., 2000). This software has proven its successful prediction of the behaviour of SFRC specimens and other composites in the past by using material relationships adopting a discrete crack approach $(\sigma-\omega)$ (Ngo and Scordelis, 1967) or smeared crack approach $(\sigma-\varepsilon)$ (Rashid, 1968) to predict the tension stiffening behaviour postcrack and was used by a number of researchers (Tlemat, Pilakoutas and Neocleous, 2006; Mirza, 2008; Syed Mohsin, 2012; Abbas et al, 2014a, b). ABAQUS can address the tensile, compressive and shear behaviour of fibrous concrete to a great level of accuracy as well as determining the cracking patterns and failure mechanism in the presence of steel fibres and reinforcement. The methodology used in this work will not model fibres discretely. Instead, fibres will be modelled as part of the concrete matrix. This approach was opted for as modelling fibres discretely can be time consuming and will produce a purely FE based model, diffi- 
cult to practically use by designers. In addition, fibrous concrete as a composite material involves the randomness of fibres inherently. This means that modelling fibres discreetly as realistic as it might be is also likely to completely miss the actual distribution and location of the fibres in a particular beam test especially for lower $V_{f}$ and longer fibres. On the other hand, modelling fibres as part of the concrete matrix can offer an easier and simpler way to derive the behaviour of the material while also taking into consideration the random distribution and dispersion of fibres by introducing factors on the composite fibrous concrete stress-strain. The latter is derived from the uniaxial tensile pullout tests. However, the main disadvantage of the homogenous composite concrete modelling method is that local failures on the mesoscale level (such as fibre pullout) are not explicitly detected unlike in the discrete fibre 3D continuum modelling method (Zhang et al., 2018).

Concrete damaged plasticity (CDP) was calibrated and chosen to model the concrete specimens of the experiments. Previous papers (Syed Mohsin, 2012; Behinaein et al, 2018) claim that both brittle cracking $(\mathrm{CBC})$ and damaged plasticity produced good results for their models. While this remains somewhat true, for the work carried out in this project CDP was deemed the more accurate and suitable tool to model reinforced and non-reinforced plain and fibrous concrete beams. This was the case as the experimental results for both tension as well as compressions tests can be used which makes CDP more realistic as compared to the crude $\mathrm{CBC}$ which assumes the behaviour of concrete to be completely elastic in compression. The other issue with $\mathrm{CBC}$ is that the performance of concrete is highly sensitive to the material shear behaviour which has to be calibrated. No material pure shear tests were carried out in this research. It should also be noted that convergence problems were very common for CBC and there was a need to use the Brittle failure criterion which might significantly affect the accuracy of the results.

The explicit dynamic solver in a quasi-static analysis is also adopted. The explicit dynamic analysis was found to be a more computationally efficient tool at solving the problems used in this project as compared with implicit solver which had a tendency to terminate. The experimental results from this thesis will be input into ABAQUS to model SFRLC structural beams. This project models the uniaxial pullout cubes and compression cylinders on ABAQUS first to calibrate both the behaviour of fibrous Lytag concrete in tension and compression. Then, these were used to model the flexural beam tests.

\subsection{Calibration of material models}

For concrete model using CDP a few important parameters need to be defined namely; Eccentricity, $\mathrm{fb} 0 / \mathrm{fc} 0$ which is the ratio of initial equibiaxial compressive yield stress to initial uniaxial compressive yield stress, $\mathrm{K}$ is the viscosity parameter and the dilation angle. The latter was found to be the single most influencing parameter on the behaviour of concrete beams for explicit CDP analysis. The dilation angle was calibrated using uniaxial compression tests on cylinders where volumetric strains for both experimental and numerical results were compared in a manner inspired by Kupfer (1974) (Szczecina and Winnicki, 2016). Other factors were determined to have little to no influence on the behaviour of plain and lightweight fibrous concrete based on the calibration work from this research and previous work (Szczecina and Winnicki, 2016; Rodriguez et al., 2013; Jankowiak and Lodygowski, 2005; Hafezolghorani et al., 2017). The behaviour of concrete in uniaxial compression and tension was taken directly from the experiments. With regards to the behaviour of plain concrete in uniaxial tension, lightweight concrete would fail abruptly once the peak is reached. However, ABAQUS requires a tension softening curve to avoid computational errors and convergence problems. For this reason, a small displacement based on a calibrated fracture energy method calculated using fib model code 2010 was used. 
With Regards to steel material model, a simple elastic-plastic stress-strain curve based on experiments is input.

\section{RESULTS AND DISCUSSION}

\subsection{Experimental Results}

Slump tests according to BS EN 12350-2 are carried out immediately after mixing the concrete to evaluate the consistency of the concrete and compare it to the consistency values recommended by Lytag. Table 2 below summarises the values of slump. Although consistent amongst each other, it can be seen that the values of slump highly exceed those recommended by Lytag $(70 \mathrm{~mm})$. This was also observed elsewhere (Lambert, 1982). In the latter, it was also explained that in a practical situation such as mixing on site, longer period of time lapses between mixing and placing allowing more of the free water to either evaporate or be absorbed by the lightweight aggregates.

It can be seen that the addition of fibres drastically reduces workability. At fibre dosage of $\mathrm{V}_{\mathrm{f}}=2 \%$, it was observed that the finishing process becomes challenging, the possibility for balling of fibres high and inhomogeneity of concrete likely. This further emphasizes that the design of mixes for fibre dosage should not exceed $\mathrm{V}_{\mathrm{f}}=2 \%$ provided that no superplasticizers or water reducing agents are used.

Overall the wet density of concrete fell in the recommended range $1910-2000 \mathrm{Kg} / \mathrm{m}^{3}$. Theoretically the addition of steel fibres should increase the density of the concrete. However, it is clear from the table below that the higher the steel fibre dosage the less the density of the concrete. This was the case as hooked end fibres tend to create air voids within the concrete lattice. This finding is also consistent with Mo et al. (2017) observations for fibres with similar geometrical properties.

\begin{tabular}{|c|c|c|c|c|c|c|}
\cline { 2 - 7 } \multicolumn{1}{c|}{} & \multicolumn{2}{c|}{ Properties of mix } & \multicolumn{3}{c|}{ Slump (mm) } & \multirow{2}{*}{$\begin{array}{c}\text { Wet Densi- } \\
\text { ty Kg/m3 }\end{array}$} \\
\cline { 2 - 7 } & W/C ratio & Fibre Type & Plain & $\mathrm{V}_{\mathrm{f}}=1 \%$ & $\mathrm{~V}_{\mathrm{f}}=2 \%$ & 2145 \\
\hline Mix 1.1 & 0.49 & & 169 & & & 2000 \\
\hline Mix 1.2 & 0.49 & 3D & 168 & 60 & & 1860 \\
\hline Mix 1.3 & 0.49 & 3D & 147 & 55 & 26 & 1934 \\
\hline Mix 1.4 & 0.49 & 5D & 150 & 50 & & 2081 \\
\hline Mix 1.5 & 0.43 & 3D & 170 & & & 2002 \\
\hline Mix 1.6 & 0.43 & & 150 & 45 & & \\
\hline
\end{tabular}

Table 2: Slumps and Wet densities

Figure 2 depicts the average normal compressive stress-strain behaviour for the cylinders. The compressive strength values for the cylinders lied within the acceptable design values for both LC30 and LC35. Young's Modulus of Elasticity was measured to be 17.8, 17.3, 18.6 and 17.6 GPa for mix 1.1, 1.2, 1.3 and 1.4 respectively. These values are lower than Eurocode 2 table 3.1.11 recommendations, which suggest 22.1 and $22.8 \mathrm{GPa}$ for both LC30 and LC35 respectively. Nonetheless, this is consistent with Lambert (1982) experiments on Lytag, which measured the modulus of Elasticity to be between 17.5 and $18 \mathrm{GPa}$ for similar strengths de- 
pending on curing conditions. The measured Poisson's ratio values ranged between 0.16 and 0.19 for all the specimens. These were consistent with Lambert (1982).

The behaviour of cylinders can be split into 3 stages. During stage A, both fibrous and plain Lytag lightweight concrete mixes experience a progressive load increase before macro cracking starts to take place in the middle section of the cylinder. This gradually reduces the tangent modulus of Elasticity and marks the start of stage B. As soon as a larger crack is formed, the cylinder specimens for plain Lytag concrete mixes 1.1 and 1.5 collapse in diagonal shear through the middle section. This is attributed to the absence of crack arresting and lateral confining mechanisms such as aggregate interlock. For fibrous lightweight concrete however, stage B illustrates a plateau-like behaviour. The macro cracking at the end of stage. At stage $\mathrm{C}$, as extensive lateral cracking dominates the post peak behaviour of the cylinders, the compressive load finally begins to decline in a ductile manner for both lightweight fibrous mixes 1.3 and 1.6. The post-peak compressive ductility is measured by $\left(\varepsilon_{\text {ult }}-\varepsilon_{\text {peak }}\right) / \varepsilon_{\text {peak }}$ with $\varepsilon_{\text {ult }}$ as the strain at $50 \%$ of the peak compressive strength. Cylinders with $\mathrm{V}_{\mathrm{f}}=2 \%$ added a post peak ductility of about 7.7 whereas those with $\mathrm{V}_{\mathrm{f}}=1 \%$ added a post peak ductility of about 3.5. Hence, as $\mathrm{V}_{\mathrm{f}}$ dosage is doubled, the ductility provided doubles as well

It can be seen that fibre reinforcement has no effect on the elastic behaviour of the cylinders and merely gradually manifest as post peak softening depending on type and dosage of fibres. Therefore, compressive strength, modulus of Elasticity and Poisson's ratio remained unaffected with the addition of fibres to the lightweight concrete mix whereas post-peak ductility substantially increased. This finding is consistent with $\mathrm{Li}$ et al. (2018) which found that random SFRC has little to no effect on the modulus of Elasticity and slight favourable or unfavourable effect on compressive strength depending on the mixing process and the geometry of fibres.

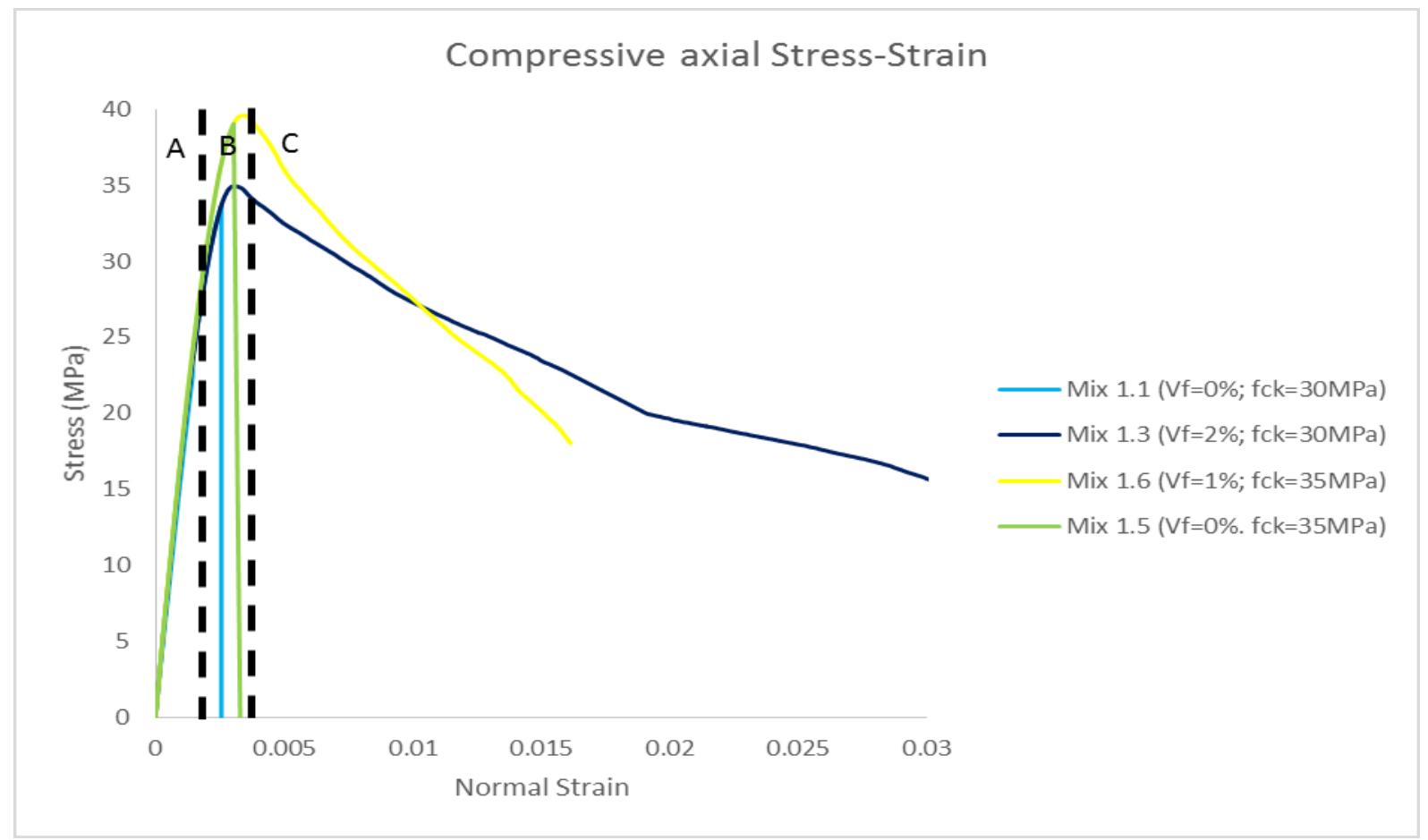

Figure 2: Compressive stress-strain behaviour for cylinders

Table 3 summarises the mean values of splitting tensile strength measured by crushing 3 cylinders per mix. It can be seen that plain lightweight concrete cylinders which included mix 1.1 and 1.5 produced splitting tensile strengths within $10 \%$ of Eurocode 2 table 11.3.1 recom- 
mendations. LC30/33 cylinders reinforced with $\mathrm{V}_{\mathrm{f}}=1 \%$ produced splitting tensile strengths equivalent to those of $\mathrm{C} 40 / 44$ while those reinforced with $\mathrm{V}_{\mathrm{f}}=2 \%$ produced tensile strengths equivalent to those of $\mathrm{C} 70 / 77$. Also, LC35/38 cylinders reinforced with $\mathrm{V}_{\mathrm{f}}=1 \%$ generated an equivalent strength of LC100. This shows that steel fibres are highly effective at upgrading the tensile resistance of lightweight concrete. Nonetheless, fibres may or may not be concentrated at the vicinity of the main crack to provide bridging reinforcement. Hence, it can be understood from the table below that some cylinders reinforced with $\mathrm{V}_{\mathrm{f}}=1 \%$ (mix 1.2) showed a lower upgraded splitting tensile strength at $20 \%$ as compared to those reinforced with $\mathrm{V}_{\mathrm{f}}=1 \%$ (mix 1.6) which was estimated to be at $47 \%$. This can also be blamed for by the possibility of developing stronger bond between 3D fibres and LC35 which has lower W/C ratio than that between $3 \mathrm{D}$ and LC30. The latter and the random distribution and dispersion of fibres remain the two most important factors governing the behaviour of fibrous lightweight concrete. This will be investigated in the pullout test.

\begin{tabular}{|l|l|l|l|l|l|}
\hline Mix & $\begin{array}{l}\text { flctm, Exp } \\
(\mathbf{M P a})\end{array}$ & $\begin{array}{l}\mathbf{f}_{\text {lctm, EC2 }} \\
\mathbf{( M P a )}\end{array}$ & $\begin{array}{l}\text { Upgraded } \\
\text { Strength due to } \\
\text { fibres (\%) }\end{array}$ & $\begin{array}{l}\text { Equivalent } \\
\text { EC2 Class }\end{array}$ & Std \\
\hline Mix 1.1 (LC30/33, Vf=0\%) & 2.67 & 2.64 & & LC30 & 0.12 \\
\hline Mix 1.2 (LC30/33, Vf=1\%) & 3.21 & 2.64 & 20.1 & LC40 & 0.10 \\
\hline Mix 1.3 (LC30/33, Vf=2\%) & 4.20 & 2.64 & 57.3 & LC70 & 0.12 \\
\hline Mix 1.4 (LC30/33, Vf=1\%) & 3.03 & 2.64 & 13.5 & LC35 & 0.49 \\
\hline Mix 1.5 (LC35/38, Vf=0\%) & 3.19 & 2.91 & & LC40 & 0.47 \\
\hline Mix 1.6 (LC35/38, Vf=1\%) & 4.70 & 2.91 & 47.3 & LC100 & 0.02 \\
\hline
\end{tabular}

Table 3: Splitting tensile strength

The figure below depicts the uniaxial tensile pullout behaviour of plain and fibrous lightweight concrete with $\mathrm{V}_{\mathrm{f}}=1 \%$. Using the curve above the peak uniaxial tensile stress of plain lightweight concrete was calculated to be $2.16 \mathrm{MPa}$ based on the cylindrical volume of concrete through which the fibre is embedded. After reaching peak, the concrete stress drops immediately to 0 at $0.8 \mathrm{~mm}$ slip which is expected for lightweight concrete due to the absence of strong aggregate interlock and any tension stiffening mechanism. The peak uniaxial tensile stress of lightweight concrete reinforced with a single $3 \mathrm{D}$ fibre equivalent to $\mathrm{V}_{\mathrm{f}}=1 \%$ was calculated to be $2.35 \mathrm{MPa}$ and $2.88 \mathrm{MPa}$ at approximately $1.2 \mathrm{~mm}$ and $1.8 \mathrm{~mm}$ slips for both LC30 and LC35, respectively based on the cylindrical volume of concrete through which the fibres are embedded. As compared to mix 1.1, mix 1.2 saw an upgrade of $9 \%$ in maximum uniaxial tensile strength due to the presence of steel fibre. After reaching peak, fibre hook straightening followed by eventual frictional pullout which took place at approximately $19 \mathrm{~mm}$ and $14 \mathrm{~mm}$ slips for mix 1.2 and 1.6, respectively. For 5D fibres, the concrete again cracks at a load of $280 \mathrm{~N}$, however due to the extensive number of mechanical hooks and higher fibre tensile strength the load peaks at a higher load of $662 \mathrm{~N}$. This is equivalent to a uniaxial tensile stress of $5.86 \mathrm{MPa}$ which is 2.6 times greater than that of plain Lytag fibrous concrete. After that, hook straightening, and frictional pullout finally took place at a slip of around $26 \mathrm{~mm}$. 


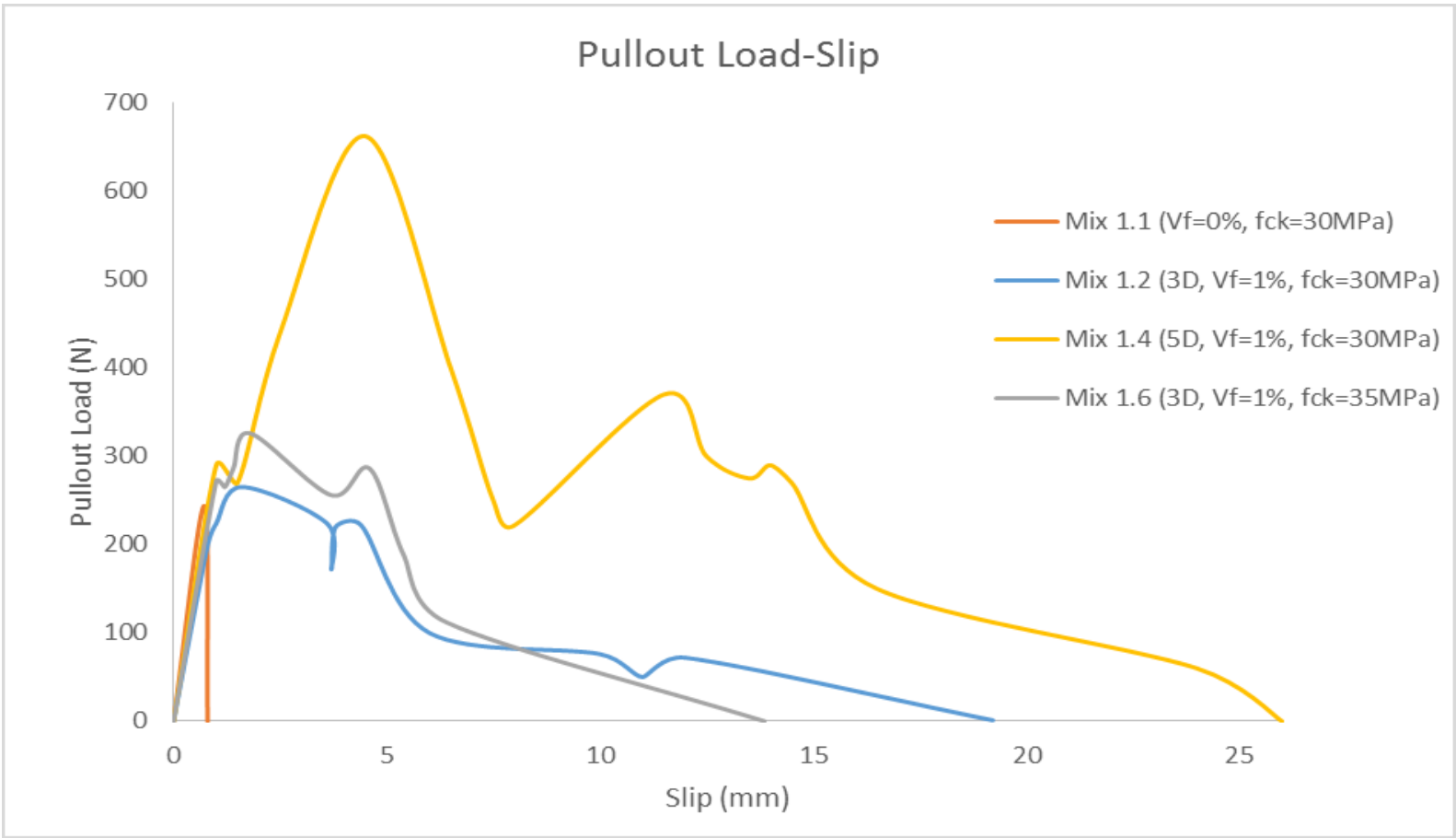

Figure 3: Pullout load-slip

Figure 4 below depicts the load-deflection curves for the 6 beams tested with different stirrup spacing and fibre dosages. All beams showed ductile behaviour as expected aside from mix 1.1 beam with inadequate spacing $\mathrm{S}=240 \mathrm{~mm}$ and $\mathrm{V}_{\mathrm{f}}=0 \%$ which failed in a brittle shear manner as predicted by Eurocode 2 shear design calculations. Hence, steel fibres are capable of altering the failure mode from shear to flexure. Using uniaxial tensile test results in combination with TR63 and Model Code 2010 flexural and shear design calculations for SFRC, it was possible to theoretically estimate the failure mode and the maximum load possible for the structural beams which agreed with the flexural beam tests results. It is observed that the ductility of the beams increases as spacing of stirrups and dosage of fibres increase. Ductility is calculated by dividing ultimate deflection at load $85 \%$ of the peak by the yield deflection at the load-deflection curve gradient before reaching peak. The ductility of fibrous beams are summarised in the table below. Relative ductility is the ductility of the beam being evaluated divided by the beam with the lowest ductility (failed in shear).

It can be seen from the table that the relative ductility for the beams with $V_{\mathrm{f}}=0 \%, \mathrm{~S}=120 \mathrm{~mm}$ and that of $\mathrm{V}_{\mathrm{f}}=1 \%, \mathrm{~S}=240 \mathrm{~mm}$ are approximately identical with the latter having slightly higher ductility. A similar trend is seen for beams with $\mathrm{V}_{\mathrm{f}}=1 \%, \mathrm{~S}=120 \mathrm{~mm}$ and that of $\mathrm{Vf}=2 \%$, $\mathrm{S}=240 \mathrm{~mm}$. This means that adding $1 \%$ of fibres is equivalent to halving the spacing of stirrups from $S=240 \mathrm{~mm}$ to $S=120 \mathrm{~mm}$. The behaviour of beams with $2 \%$ fibre volume fraction is of an elastic plastic nature.

\begin{tabular}{|c|c|c|}
\hline Beam & Ductility & Relative ductility \\
\hline $\mathrm{V}_{\mathrm{f}}=0 \% ; \mathrm{S}=240 \mathrm{~mm}$ & 1.57 & 1 \\
\hline $\mathrm{V}_{\mathrm{f}}=0 \% ; \mathrm{S}=120 \mathrm{~mm}$ & 1.91 & 1.21 \\
\hline $\mathrm{V}_{\mathrm{f}}=1 \% ; \mathrm{S}=240 \mathrm{~mm}$ & 1.99 & 1.26 \\
\hline $\mathrm{V}_{\mathrm{f}}=1 \% ; \mathrm{S}=120 \mathrm{~mm}$ & 2.69 & 1.71 \\
\hline $\mathrm{V}_{\mathrm{f}}=2 \% ; \mathrm{S}=240 \mathrm{~mm}$ & 2.83 & 5.87 \\
\hline $\mathrm{V}_{\mathrm{f}}=2 \% ; \mathrm{S}=120 \mathrm{~mm}$ & 9.22 & \\
\hline
\end{tabular}

Table 4: Ductility and Relative Ductility of the beams 


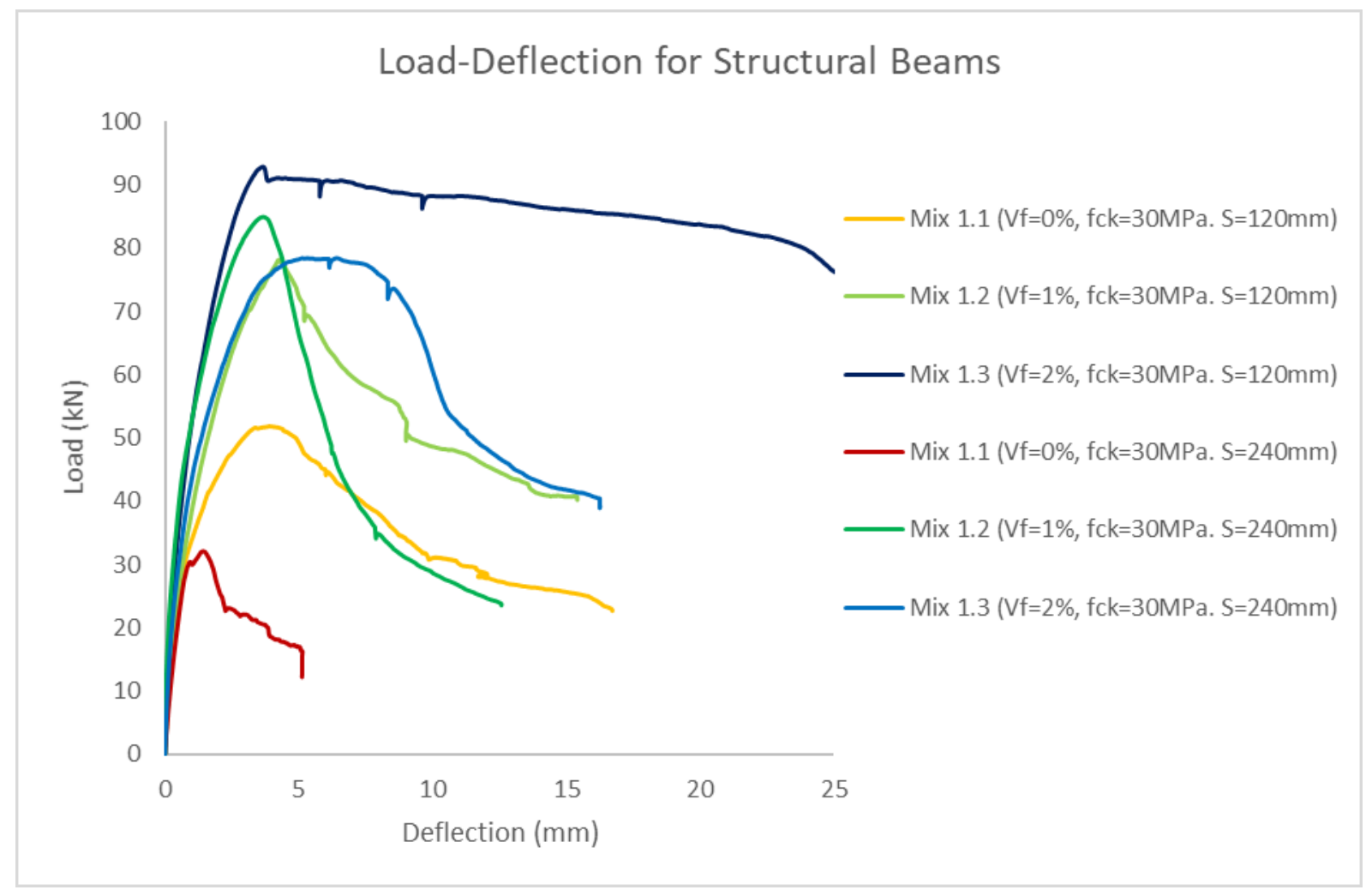

Figure 4: Load-deflection for flexural beam

\subsection{Numerical Results}

Figure 5 below depicts the pullout stress-displacement of plain concrete from ABAQUS in comparison with experimental fib model code derived curve. It is noticed that ABAQUS is capable of predicting with a reasonable approximation the uniaxial tensile stress-cracking displacement until the load drops to about $5 \%$ where an asymptote is seen to avoid numerical convergence errors.

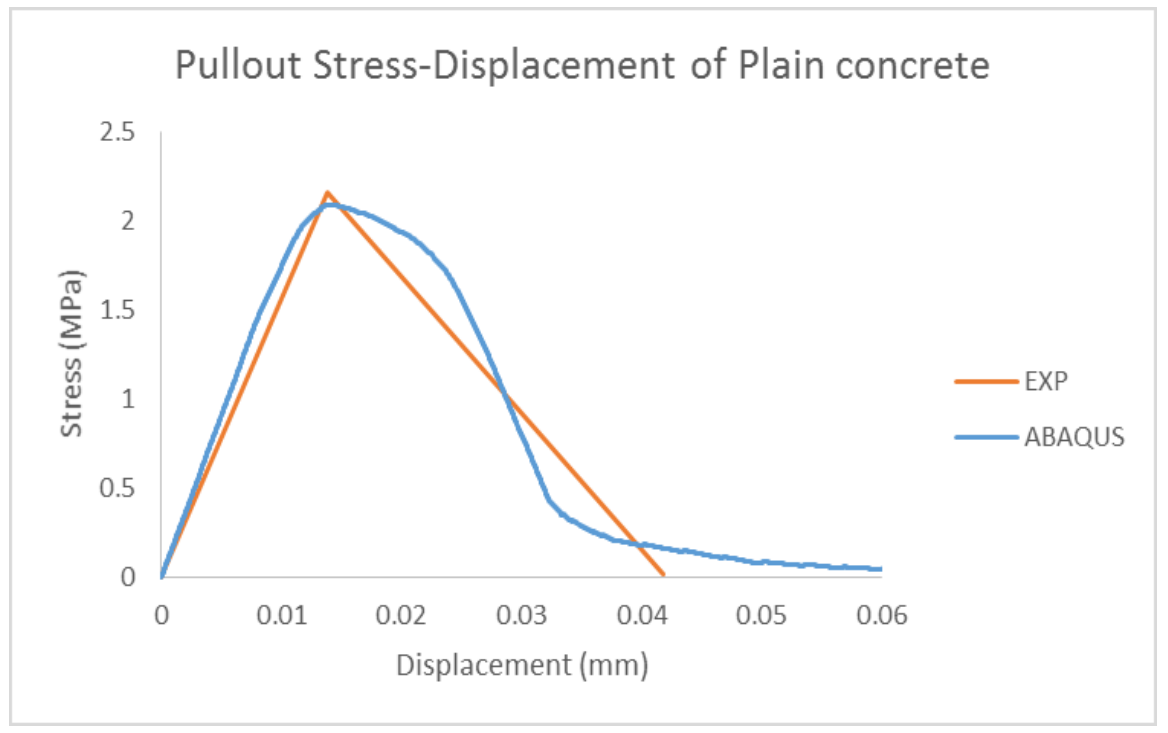

Figure 5: Derived Stress-Displacement using ABAQUS 
For the compression cylinders, the ABAQUS and Experimental stress-strain behaviour is almost perfectly identical aside from 5\% difference at the peak strength where the ABAQUS prediction is more conservative than the experimental solution. Figure 6 illustrates the latter relationship for plain lightweight concrete.

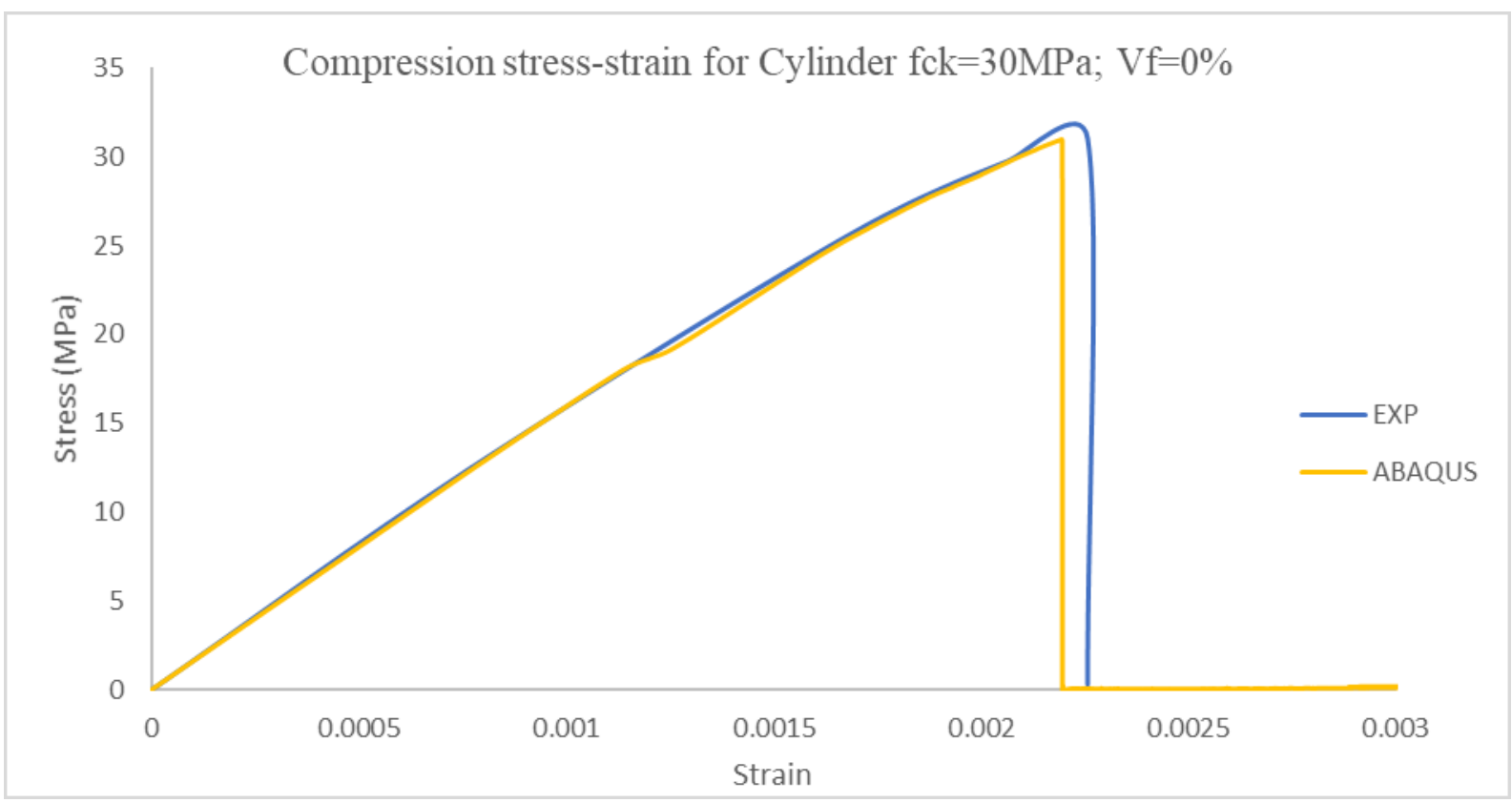

Figure 6: Compression stress-strain for ABQUS vs EXP

Figure 7 below show the cracking pattern for the reinforced beam with stirrup spacing $\mathrm{S}=120 \mathrm{~mm}$. The patterns are similar to experiments

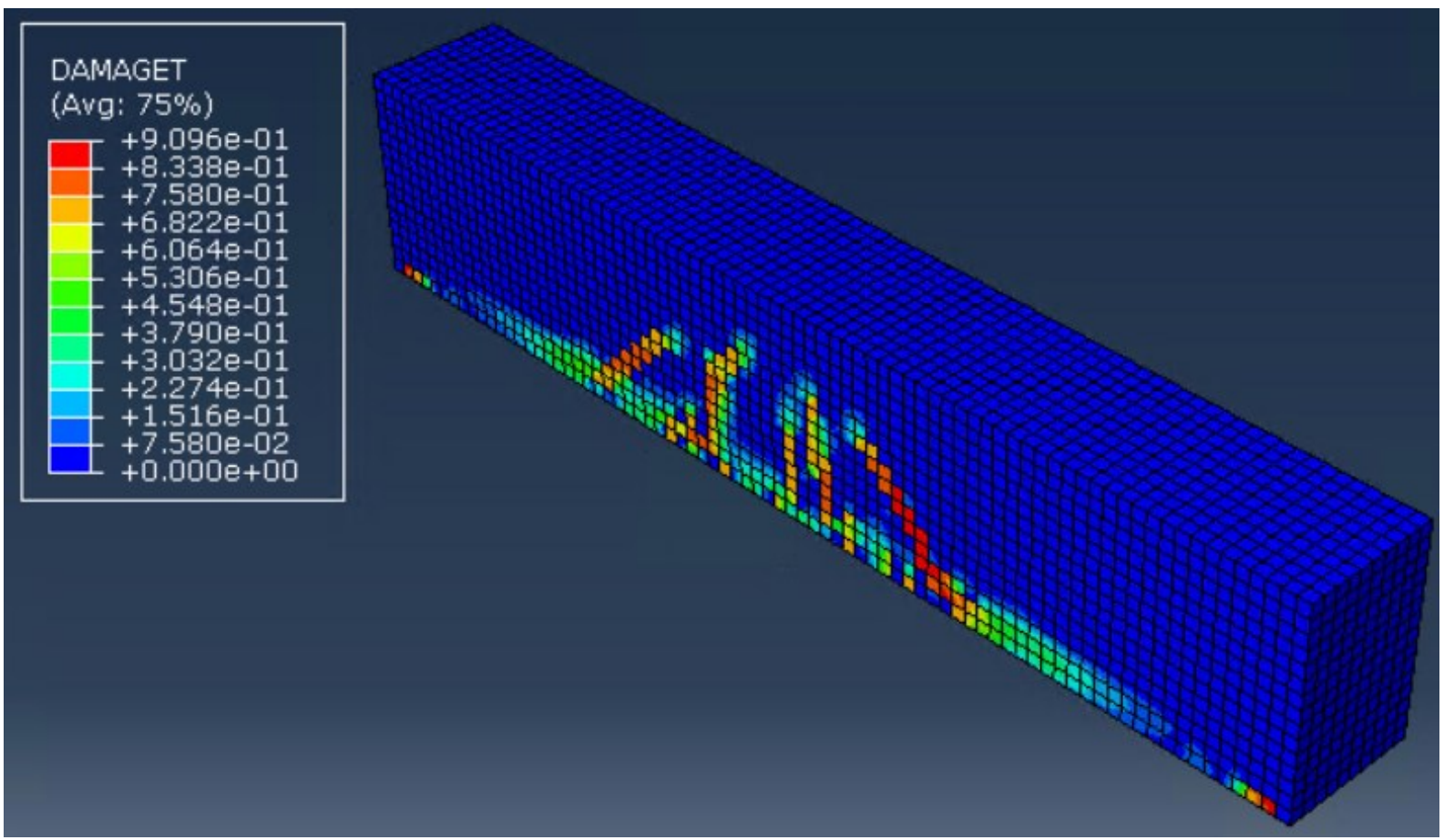

Figure 7: Development of flexural cracks for beam with $S=120 \mathrm{~mm}$ 
Figure 8 below depicts the load-deflection relationship of the beam reinforced with $S=120 \mathrm{~mm}$. It can be seen that the approach employed predicted accurate results.

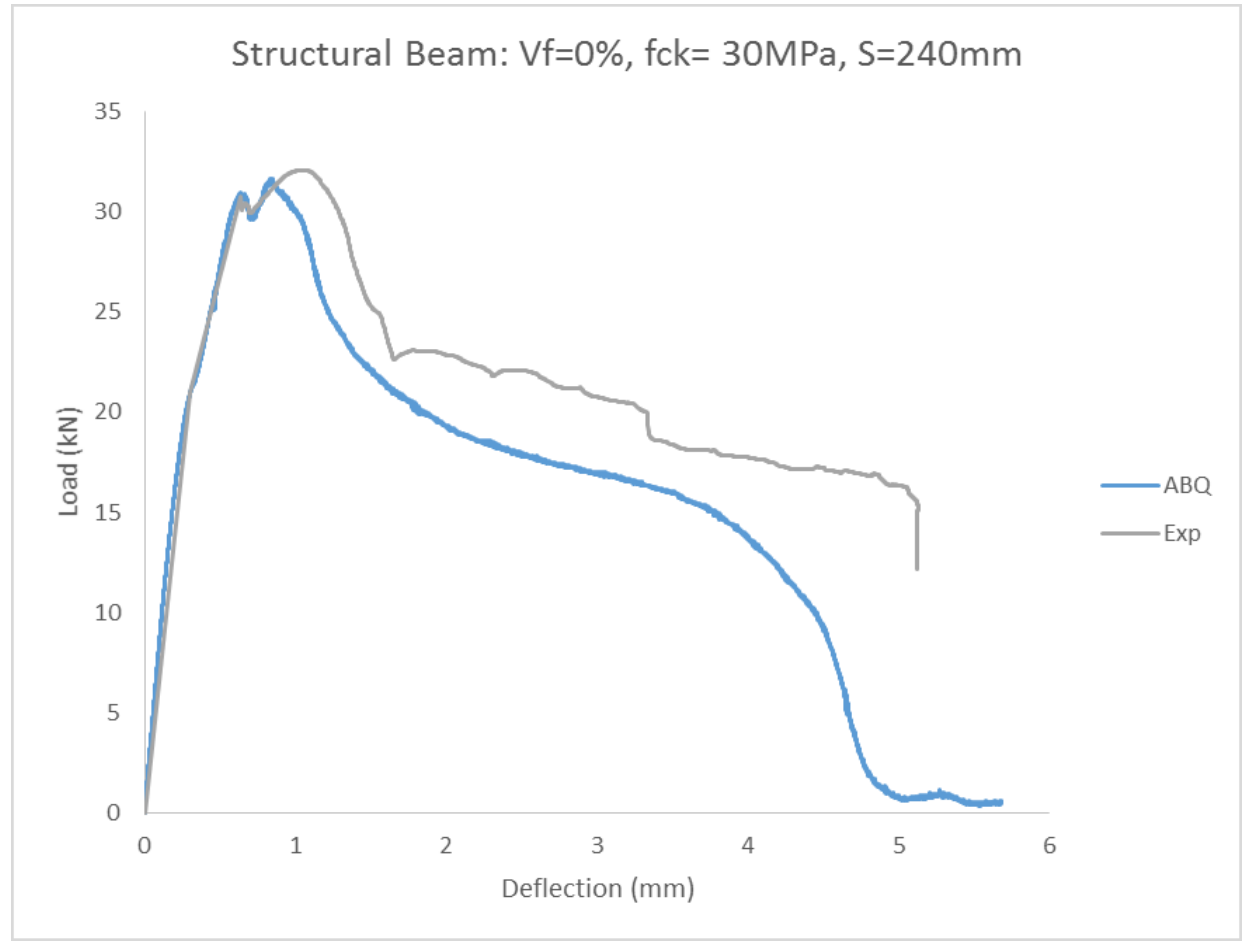

Figure 8: Load-deflection relationship of beam reinforced with $S=240 \mathrm{~mm}$

\section{CONCLUSIONS}

- Density and workability are negatively influenced by the addition of steel fibres.

- Compression peak strengths are unaffected by fibres however post peak ductility is enhanced.

- Beam load carrying capacity and ductility are enhanced while mode of failure changes from shear to flexure as $\mathrm{V}_{\mathrm{f}}$ increases. Fibres can adequately replace stirrups.

- The designed direct tensile test was successful at showing the behaviour of concrete and its bond with different fibres.

- The approach adopted for the numerical modelling shows good correlation between experimental and numerical results.

\section{REFERENCES}

[1] Abdallah Sadoon, David W.A Rees, Sayed Hamidreza Ghaffar and Mizi Fan. (2018). Understanding the effects of hooked-end steel fibre geometry on the uniaxial tensile behaviour of self-compacting concrete. Construction and Building Materials. 178, 484-494.

[2] ABAQUS Version 6.7 Documentation, 2007. [Online]. Available at http://www.engine.brown.edu:2080/v6.7/index.html.

[3] Abbas, A., Syed Mohsin, S. and Cotsovos, D. (2014a). Seismic response of steel fibre reinforced concrete beam-column joints. Engineering Structures, 59, pp.261-283. 
[4] Abbas, A., Syed Mohsin, S., Cotsovos, D. and Ruiz-Teran, A. (2014b). Shear behaviour of steel-fibre-reinforced concrete simply supported beams. Proceedings of the Institution of Civil Engineers - Structures and Buildings, 167(9), pp.544-558.

[5] Balendran, R., Zhou, F., Nadeem, A. and Leung, A. (2002). Influence of steel fibres on strength and ductility of normal and lightweight high strength concrete. Building and Environment, 37(12), pp.1361-1367.

[6] Behinaein, Demetrios M. Cotsovos and Ali A. Abbas. (2018). Behaviour of steel-fibrereinforced concrete beams under high-rate loading. Computers and concrete. 22 (3), 337353.

[7] Campione, G. and La Mendola, L. (2004). Behavior in compression of lightweight fiber reinforced concrete confined with transverse steel reinforcement. Cement and Concrete Composites, 26(6), pp.645-656.

[8] Campione, G. (2014). Flexural and Shear Resistance of Steel Fiber-Reinforced Lightweight Concrete Beams. Journal of Structural Engineering, 140(4), p.04013103.

[9] Dias-da-Costa, D., Carmo, R., Graça-e-Costa, R., Valença, J. and Alfaiate, J. (2014). Longitudinal reinforcement ratio in lightweight aggregate concrete beams. Engineering Structures, 81, pp.219-229.

[10] Di Prisco, M., Colombo, M. and Dozio, D. (2013). Fibre-reinforced concrete in fib Model Code 2010: principles, models and test validation. Structural Concrete, 14(4), pp.342-361.

[11] Gao, J., Sun, W. and Morino, K. (1997). Mechanical properties of steel fiber-reinforced, high-strength, lightweight concrete. Cement and Concrete Composites, 19(4), pp.307-313

[12] Gerritse, A. (1981). Design considerations for reinforced lightweight concrete. International Journal of Cement Composites and Lightweight Concrete, 3(1), pp.57-69.

[13] Grabois, T., Cordeiro, G. and Filho, R. (2016). Fresh and hardened-state properties of self-compacting lightweight concrete reinforced with steel fibers. Construction and Building Materials, 104, pp.284-292.

[14] Hafezolghorani, Farzad Hejazi, Ramin Vaghei, Mohd Saleh Bin Jaafar and Keyhan Karimzade. (2017). Simplified Damage Plasticity Model for Concrete. Structural Engineering International. 1 (1), 68-78.

[15] Hibbitt, Karlsson and Sorensen Inc (2000) Abaqus User's Manual, Vol. II, Version 6.1, PP 11.5.1.1-11.5.1.14 (USA).

[16] Iqbal, S., Ali, A., Holschemacher, K. and Bier, T. (2015). Mechanical properties of steel fiber reinforced high strength lightweight self-compacting concrete (SHLSCC). Construction and Building Materials, 98, pp.325-333.

[17] Javier Rodríguez, Francisco Martínez, and Joaquín Martí. (2013). Concrete Constitutive Model, Calibration and Applications. 2013 SIMULIA Community Conference. N/A (N/A), $1-1$.

[18] Kang, T. and Kim, W. (2010). Shear strength of steel fiber-reinforced lightweight concrete beams. Oklahoma: Korea Concrete Institute, pp.1386-1392.

[19] Kang, T. and Kim, W. (2010). Shear strength of steel fiber-reinforced lightweight concrete beams. Oklahoma: Korea Concrete Institute, pp.1386-1392.

[20] Kodur Venkatesh, Roya SOlhmirzaei, Ankit Agrawal, Esam M Aziz and Parviz Soroushian. (2018). Analysis of flexural and shear resistance of ultra high performance fiber reinforced concrete beams without stirrups. Engineering Structures. 174, 873-884.

[21] Krenchel, H. Fiber spacing and specific fiber surface. In: Neville A M, ed. RILEM Symposium on Fiber Reinforced Cement and Concrete. London: The Construction Press, 1975, 69-79. 
[22] Lambert, G, (1982) Properties and behaviour of structural lightweight (Lytag-sand) concrete. $\mathrm{PhD}$ thesis, University of Sheffield.

[23] Li Fang-Yuan, Cheng-Yuan Cao, Yun-Xuan Cui, and Pei-Feng Wu. (2018). Experimental Study of the Basic Mechanical Properties of Directionally Distributed Steel FibreReinforced Concrete. Advances in Materials Science and Engineering. 2018 (1), 1-11.

[24] Libre, N., Shekarchi, M., Mahoutian, M. and Soroushian, P. (2011). Mechanical properties of hybrid fiber reinforced lightweight aggregate concrete made with natural pumice. Construction and Building Materials, 25(5), pp.2458-2464.

[25] Lyag (2011). Technical manual. London: Lytag ltd.

[26] Mo, K., Goh, S., Alengaram, U., Visintin, P. and Jumaat, M. (2017). Mechanical, toughness, bond and durability-related properties of lightweight concrete reinforced with steel fibres. Materials and Structures, 50(1).

[27] Mirza, O. (2008). BEHAVIOUR AND DESIGN OF HEADED STUD SHEAR CONNECTORS IN COMPOSITE STEELCONCRETE BEAMS. BEng (Hons). University of Western Sydney, Australia.

[28] Ngo, D. and Scordelis, A.C. (1967). "Finite Element Analysis of Reinforced Concrete Beams," Journal of ACI, Vol. 64, No. 3, pp. 152-163.

[29] Ritchie A., Kayali O. 1975. The effects of fiber reinforcement on lightweight aggregate concrete. In: Neville A (ed.), Proceedings of RILEM Symposium on Fiber Reinforced Cement and Concrete, The Construction Press Ltd, p. 247-56.

[30] Robins, P., Austin, S., and Jones, P., 2002. Pull-out Behaviour of Hooked Steel Fibres. Materials and Structures, RILEM, 35; p. 4343-442

[31] Romualdi, James P., and Mandel, James A., "Tensile Strength of Concrete Affected by Uniformly Distributed and Closely Spaced Short Length of Wire Reinforcement," AC1 JOURNAL, Proceedings V. 61, No. 6, June 1964, pp. 657-671.

[32] Soroushian and Lee. (1990). Tensile Strength of Steel Fiber Reinforced Concrete: Correlation with Some Measures of Fiber Spacing. ACI materials journal. 87 (6), 542-546.

[33] Swamy, N., Jones, R. and Chiam, A. (1993). Influence of Steel fibers on the Shear Resistance of Lightweight Concrete I-Beams. ACI Structural Journal, 90(1), pp.103-114.

[34] Syed Mohsin SM (2012) Behaviour of Fibre-reinforced Concrete Structures under Seismic Loading. PhD thesis, Imperial College London, London, UK.

[35] SZCZECINA and WINNICKI. (2016). SELECTED ASPECTS OF COMPUTER MODELING OF REINFORCED CONCRETE STRUCTURES. ARCHIVES OF CIVIL ENGINEERING. 62 (1), 51-64.

[36] The Concrete Society, 2007. Guidance for the Design of Steel-Fibre-Reinforced Concrete. Technical Report No. 63. Cement and Concrete Industry.

[37] Tlemat, H., Pilakoutas, K. and Neocleous, K. (2006). Stress-strain characteristic of SFRC using recycled fibres. Materials and Structures, pp.365-377.

[38] Tomasz JANKOWIAK, Tomasz LODYGOWSKI. (2005). IDENTIFICATION OF PARAMETERS OF CONCRETE DAMAGE PLASTICITY CONSTITUTIVE MODEL. FOUNDATIONS OF CIVIL AND ENVIRONMENTAL ENGINEERING. 6 (unknown), 53-69.

[39] Zhang, Y.J. Huang, Z.J. Yanga, S.L. Xua, X.W. Chen. (2018). A discrete-continuum coupled finite element modelling approach for fibre reinforced concrete. Cement and Concrete Research. 106 (2018), 130-143.

[40] Zienkiewicz OC and Taylor RL (2005) Vol. 2: The Finite Element Method for Solid and Structural Mechanics, 6th edn. Butterworth-Heinemann, Oxford, UK. 